\title{
History and Social Sciences Teacher's Professional Activity in the Context of IT-Development of Education
}

\author{
Albina R. Fayzullina ${ }^{1} \&$ Firuza A. Saglam ${ }^{2}$ \\ ${ }^{1}$ Kazan (Volga Region) Federal University, Kazan, Russia \\ ${ }^{2}$ Institute of Economy, Management and Law, Kazan, Russia \\ Correspondence: Albina R. Fayzullina, Kazan (Volga Region) Federal University, 420008, Kazan, \\ Kremlyovskaya Street 18, Russia,. E-mail: fazalbina@rambler.ru
}

\author{
Received: June 15, 2015 Accepted: June 24, 2015 Online Published: June 30, 2015 \\ doi:10.5539/jsd.v8n7p107 URL: http://dx.doi.org/10.5539/jsd.v8n7p107
}

\begin{abstract}
The urgency of a studied problem is caused by requirements of a federal state educational standard of the general education assuming a new approach to the development of a lesson in the conditions of the modern information-educational environment. In this regard it is necessary for a teacher to seize appropriate technology of preparation of a lesson. The article is aimed at the analysis of didactic characteristics and possibilities of the information-educational environment by means of which it is possible to build effectively the educational process in new conditions. The leading approach to the research of this problem was system-activity approach, which allows realizing the principles of designing a lesson in the information-educational environment, being an important tool of the analysis of planned educational results. The article disclosed the role, presented the content and revealed the features of professional activity of the teacher in the conditions of informatization of education and also emphasized their influence on the achievement of planned educational results. The materials of the article can be useful to teachers of history and social science while designing a lesson in the information-educational environment, at definition and analysis of planned educational results, selection of types of the educational activity corresponding to planned educational results and selection of tutorials for realization of these types of educational activity.
\end{abstract}

Keywords: information-educational environment of a lesson, organizational structure of training, planned educational results, educational technologies, info-communicative technologies of training

\section{Introduction}

The main factors influencing the development of education today are the turn to the identity of trainees (personality development - the sense and purpose of modern education) and globalization processes. These requirements are connected with the change of the ideas of the essence of personal readiness to perform professional functions and social roles. The introduction of new federal state educational standards providing conditions for preparation of the personality, capable of life in changing social and economic conditions (Novikov, 2005) became the consequence of these changes.

It is important to understand that the traditional process of training at school, undoubtedly, yielded educational results, but those results were demanded by former society with its values and ideals. New educational results can be received only in the conditions of training in the information-educational environment providing information and methodical conditions of realization of an educational program.

According to educational standards of the general education the information-educational environment of educational institution should contain a complex of information-educational resources, including digital educational resources, a set of technological means of information and communication technologies, a system of modern pedagogical technologies providing training in the modern information-educational environment (Chernobay, 2011.).

An educational process in the information-educational environment at lessons of history and social science, based on the use of means of info-communicative technologies, in comparison with traditional process of training allows:

- increasing possibilities of the choice of means, forms and rate of studying of educational areas;

- providing access to various information from the best libraries, museums; giving a chance to listen to lectures of 
leading scientists and asking them questions, taking part in work of virtual schools;

- raising the interest of pupils to studied subjects with the help of presentation, entertaining, interactive form of presentation of a training material, strengthening of inter-subject connections;

- increasing motivation to independent training, development of critical thinking;

- using mutual training methods (discussion of educational problems at forums, in chats, operative obtaining helps) more actively;

- developing an educational initiative, abilities and interests of pupils;

- creating installation for continuous life-long education (Selevko, 1998).

From the definition of the information-educational environment of an educational institution we allocate a concept «the information-educational environment of a lesson». The following characteristics providing the achievement of planned educational results are inherent in it: flexibility of organizational structure of training, integrity, openness, poly-functionality, variability, visualization, interactivity (Ivanov \& Osmolovsky, 2011).

Let's stop in detail at these characteristics significant for the organization of educational process.

Flexibility of organizational structure of training. Specifics of teachers' professional activity in working conditions in new information-educational environment is defined, in particular, by the fact that the environment has flexible structure and a set of tutorials changing, depending on educational technologies applied by the teacher. Actually the information-educational environment of a lesson can be considered as a peculiar designing set which elements can be used by a teacher to create its options (versions) most adequately, satisfying the requirements of educational tasks specific for each fragment of the mastered contents. A methodical skill of the teacher in this case is defined by his ability to form various versions of the environment depending on features of the content and educational problems of a concrete training material development (Chelyshkov, et al, 2011).

Integrity, i.e. internal unity of the environment components thanks to which the expedient logic of the process of training expansion is provided: planned educational results, related with both teachers' and pupils' activity, are defined. Integrity results from a conscious activity of the subjects of an educational process. It is designed according to the invariant maintenance of a training material, optimum methods and ways of training promoting the achievement of the training purposes (Ivanenko, et al, 2015).

Openness as the result of the environment interaction with information-educational space. Unlimited resources allow organizing the variable training answering to subject positions and inquiries of all educational space participants (Grigoriev, 2008).

Poly-functionality. The environment can be a source of knowledge and at the same time promote the organization of various forms of independent informative pupils' activity.

Variability. Each pupil is given an opportunity to build the individual educational trajectory himself and to move on it, reaching the planned educational results. Besides, variability also assumes various selection of the contents fragments depending on objectives. Such approach is caused by redundancy of the information-educational environment (Moryak, 2000).

Visualization - presentation of the physical phenomenon or process in shape, convenient for visual perception.

Interactivity provides conditions for operative control of educational achievements, access to various sources of educational information, organization of individual school students' work, development of their informative independence and creativity by means of info-communicative technologies, possibilities of the use of new pedagogical tools for the solution of educational tasks (thereby expanding the circle of solved tasks), transition possibilities to essentially new models of studied processes and objects with possibilities of their operative analysis, research and experiments with them etc. (Chernobay 2009; Levina, et al, 2015).

In addition, the information-educational environment of a lesson allows realizing didactic possibilities of innovative pedagogical technologies, to organize effectively individual and collective work of pupils, providing purposeful development of their independent and informative activity.

Thus, planning of an educational process today is a chain of carefully selected and interconnected structural components assuming the analysis and selection of planned educational results actual for this grade level, selection of educational activity types corresponding to allocated educational results, and tutorials for realization of these types of educational activity.

It is obvious that this approach gives the teacher a chance to build history and social science lessons in a new way under condition of the use of info-communicative technologies means in the course of training. In its turn, it 
demands reconsideration of a role and nature of teachers' professional activity in conditions of working in new information-educational environment.

\section{Methodological Framework}

\subsection{Research Problems}

During the research it was necessary to solve the following problems:

1) to characterize methodical principles and receptions of designing the information-educational environment and describe its didactic characteristics and possibilities by means of which it is possible to build effectively an educational process in new conditions.

2) to prove the role, content and nature of professional activity of a teacher of history and social science in working conditions in the modern information-educational environment and analyze the influence of these changes on the achievement of planned educational results.

\subsection{Theoretical and Methodological Framework of the Research}

Theoretical and methodological framework of the research was conceptual provisions of pedagogy and didactics, relating to the concept definition of the information-educational environment of a lesson, organizational structure of training, planned educational results, educational technologies, info-communicative technologies of training. To analyze the designated problem a system-activity approach was applied, it was accompanied by general scientific and special methods, tools of a pedagogical science, comparative in particular. The selection of the content elements was carried out on the basis of federal state educational standards, programs of base and profound levels of history and social science studying at school.

\section{Results}

Recently the educational process at school was planned by the teacher according to the content of education (program), age and students' learning level. These are certainly important components of teaching process planning. Nevertheless the active role in training was played by the teacher, the pupil was considered an object, necessary to influence to reach the planned results. The methods connected with transfer of knowledge and formation of abilities on their application in standard habitual situations dominated. The pupil was the recipient of ready information which turned into knowledge at assimilation. Identical textbooks for the whole class pupils provided limited possibilities for profound studying of interesting subjects. Actually they were the scenario of the process of training (Chernov, 2001).

Today the educational process is aimed at the creation of experience to deal with information, its expedient application providing self-development and self-updating of the pupil. The development of abilities of independent knowledge acquisition and application according to the personal purposes and requirements, the solution of problems actual for pupils is the main aim. The great value is allocated for the formation of the ways of the activity applicable both within the educational process and at the solution of problems in real life experiences (Karnaukhov, 1997).

The process of training is planned, organized and lead by the teacher of history and social science as the result of his joint activity with pupils according to the content of education (program), personal experience, informative interests and needs of children. The preference is given to the methods of training which help to master universal ways of activity (informative, valuable-oriented, practical, communicative) (Solovyeva, 2003).

Creation of the educational process in the information educational environment cardinally changes the participants' roles and nature of their modern interaction.

The nature of interaction of the educational process participants is reflected in the principles of cooperation pedagogy. The fundamental principles are: democratic character (freedom of choice, equality, personal character of relations); openness (refusal of traditional role interaction, freedom of criticism); alternativeness (plurality of contents and ways of activity); dialogism (poly-logical); reflexivity (understanding of the purposes, contents, types of activity and interaction nature). In such environment understanding and recognition of the pupil based on aspiration of the teacher to take the pupil's place is reached.

The roles of educational process participants also become different. Initially school students plunge into activity where they act its active subjects, and the teacher is the organizer of communication. One of the major conditions which are simulated by the teacher is the creation of certain difficulties in carried-out activity of the students. The arising need for overcoming difficulties deduces the pupil (in the beginning with the help of the teacher, and then it is independent) in the reflection where the analysis of the activity before difficulty is carried out, then he carries out the search of the reasons of the arisen difficulty, a problematization of the former activity and change of activity 
norm. The school student in this case acts the subject of the activity unlike the traditional educational environment where he played an object role. It is important to emphasize that in the new information-educational environment the teacher becomes the carrier of modern pedagogical thinking and principles of the cooperation pedagogy, a reflecting professional capable at designing and redesigning (depending on the requirement of the educational process and each definite pupil) educational process according to the specified principles. Besides, in the conditions of educational process in the information-educational environment such functions of the teacher as control, correction, training of standard abilities, can be realized by means of info-communicative technologies that essentially facilitates s professional activity (Chernobay, 2010; Tuhvatullin, 2015).

As a whole the realization of such approach leads to emergence of steady interest to study and informative motives in school students. Such qualities are formed: need for self-training, self-development; ability to gain independence in educational activity with understanding of an individual responsibility in it; need for the collective work aimed at receiving uniform result, etc. It is necessary to stress that the teacher in the conditions of educational process in the information-educational environment plays several roles - a participant of pupils' designing activity, a developer or performer of educational projects, a designer of training courses, an expert of pupils' educational activity, an organizer of pedagogical support for pupils during the process of training, a tutor (Khayrutdinov, 2014).

Thus, we see that in new conditions the role and nature of teachers' professional activity changes essentially. In this regard the teacher should know didactic principles of such lesson creation.

\section{Discussions}

According to the requirements of new educational standards the teacher of history and social science should build educational process, using all possibilities of the information-educational environment (Bespalko, 2008), including the possibility of info-communicative technologies, and be able respectively:

- to operate the educational process;

- to create and edit spreadsheets, texts and presentations;

- to create and edit interactive training materials, educational resources, creative works with statistical and dynamic graphic and text objects individually and collectively (the multiuser mode) ;

- to visualize historical data (to create tapes of time, etc.);

- to work with geo-information systems, cartographical information, plans of objects and districts;

- to place, systematize and store (accumulate) materials of educational process (including students' and teachers' ones, information resources used by participants of educational process);

- to carry out monitoring and fix the course of educational process and the development results of the main educational program of the general education;

- to use different types and forms of knowledge and skills control, to carry out adaptive (differentiated) preparation for the state (total) certification;

- to carry out interaction between participants of the educational process, including remote (by means of local and global networks) use of the data formed during educational process for the solution of problems of educational activity management.

While designing the educational process in the modern information-educational environment it is necessary to remember that it should meet important didactic principles, the content of which is optimized from positions of an activity approach. Didactic principles of creating a lesson in the information-educational environment are an important tool of planned educational results analysis. Now the maintenance of principles of scientific character, visualization, consistency, activity, cooperation, consciousness and individualization (Choshanov, 2011) is concretized and presented at tool level.

Let's consider the maintenance of each of them in detail.

The principle of scientific character is one of the basic didactic principles, in modern view it defines both the selection of training material content and the ways of its assimilation adequate to scientific knowledge. According to this principle pupils should receive skills of scientific search, master modern methods of knowledge. It leads to the requirement to fill the educational process in educational environment with such contents which can be acquired effectively (used) only by means of info-communicative technologies. It should be especially noted that the content of such educational process should become the means to achieve planned educational results not its purpose, (Mikheyev \& Chekunov, 2008; Shmelyova, 2015).

The principle of scientific character leads to the requirement of problem-activity approach to the educational 
process in the information-educational environment. Such model of training puts a student on the position of the researcher, designer, project-maker, participant of communication, organizer of communication, promotes the development of analytical and logic thinking. The brunch defined by this principle promotes the achievement of personal and inter-subject results effectively.

The principle of visualization indicates the need for creation of sensual idea of a studied object in its modern treatment, makes the demand to show the model of a studied object or process in shape, which allows opening essential communications and object relations accurately. Such communications and model relations can be underlined and strengthened by possibilities of means of info-communicative technologies (Andreev, 2004).

The most important conclusion which follows from modern understanding of a principle of visualization consists in the fact that in the information-educational environment based on the use of info-communicative technologies it is possible and necessary not only to show the object of studying, but also to organize students' activities for transformation of the object either in the form of a model or the process of completing, or in the form of modification and redesigning.

In modern didactics a principle of consistency (Novikov, 2008) is especially allocated. It includes the ideas of a general scientific method of consistency, logic of system disclosure of objects and the phenomena of studied reality. According to this principle it is necessary to allocate in the objects or phenomena represented by means of info-communicative technologies the basic structural elements and essential communications between them, which allows imagining this object (phenomenon) in a complete way.

On the contrary, if it is supposed to form abilities to solve a heuristic problem, it is necessary to give the child an opportunity to construct the algorithm of actions independently.

The principle of an individual approach in modern understanding is based on the ideas of a personal approach to the trainee as to the subject of activity (Rams, 1981). The content of this principle is represented as a system of individualized receptions and ways of cooperation of the teacher and pupils.

The principle of cooperation reflects joint activity of the teacher and pupils when each participant carries out certain functions, thus, first of all, aspires to create conditions for development of school students which should be focused on achievement of new educational results (Gundyrev, 2006).

Projecting an educational process in the information-educational environment, the teacher does not simply select methods, technologies, tutorials ensuring dealing with a concrete fragment of the educational content, but creates a uniform didactic complex, thereby providing one of the most important characteristics of the information-educational environment - integrity (Smirnova, 2012; Stolyarov, 2015).

An educational process in the information-educational environment is under construction as the integrated system consisting of many components which correspond to lesson and research activity, measurement, control and evaluation of training results. The most important quality of an educational process in such environment basing upon the use of means of info-communicative technologies is its integrity and also interrelation of all the components - blocks.

It is worth remembering that an important element of a lesson in the information-educational environment is a textbook. The educational-methodical complex comes to change former, traditional textbooks. The complex includes electronic appendixes, means of methodical support, Internet support of the educational process and many other things. The development of information and communication technologies allows claiming that electronic educational resources will take a worthy place. Therefore pedagogically reasonability of the choice of educational editions depends on the teacher. He should learn to define, what resources will be included into the complex, what resources should be involved in each stage to provide integrity of educational process in the information-educational environment. Thus it is necessary to give preference to resources which are methodically competently built, open the content of education according to the same logic with the base textbook, do not duplicate, but enrich and deepen it. The actions mentioned are carried out by the teacher and are a part of a designing component of professional activity that proves the importance of its formation once again.

We come to the conclusion that didactic principles of creating a lesson in the information-educational environment are an important pedagogical tool in teacher's preparation of such lesson and they are especially important for the analysis of planned educational results.

\section{Conclusion}

The research carried out according to the goals and tasks allows formulating the following conclusions.

1. The teacher's designing the educational process in the information-educational environment demands different 
approaches not only to planning new educational results, but also to selection of the training content, methods and forms of educational process organization. It is important to notice that the content of training aimed at receiving a concrete educational result becomes the means of this result achievement.

2. At a formation stage of pupils' complete approach to the process of educational situations solution it is necessary to give special attention to working off separate actions by means of a specially selected system of exercises. This system can include exercises which are aimed at establishment of semantic connection between the basic data, search of necessary data, development of "a plot" of an educational situation, comparison and choice of the rational decision from the set of decisions offered, the structural analysis of a situation, recognition of the fact of a mistake, definition of the cause of an error etc.

3. The following methods of training are particularly effective at a lesson in the information-educational environment: training on the basis of information resources, an associative method, methods based on the use of artificial intelligence (a method of compelled assumption, a precedent method, educational computer modeling, training by means of teleconferences, etc.).

4. The methods of training applied in the conditions of educational process, constructed in the information-educational environment, are focused mainly on the achievement of new educational results. These results present the abilities to reveal, formulate and analyze a problem, put forward and estimate a hypothesis, put questions, create models of simple phenomena and processes, use methods of creative solution of tasks, classify, define urgency and practical importance of the informative activity and many other ones. It is extremely important for achievement of new educational results that these methods strengthen integration of separate subjects what is mostly available in the conditions of educational process in the information-educational environment.

5. The use of means of info-communicative technologies within a traditional model of training is incapable at realizing considerable didactic potential of these means, and, what is particularly important, does not give a guarantee of receiving essential new educational results. In this regard it is necessary for the teacher to realize the possibilities of means of info-communicative technologies at a lesson, their didactic potential. It is possible to claim that application of means of info-communicative technologies allows:

- strengthening motivation, increasing interest and expanding informative needs of trainees;

- providing individualization, creating preconditions for transition to personally-focused training;

- increasing training interactivity, developing dialogical nature of educational process;

- strengthening presentation in training, raising the level of visualization of a studied material;

- expanding a circle of educational tasks used in training;

- including in informative activity an arsenal of new methods based on the use of info-communicative technologies;

- creating possibilities for the use of new sources of educational information (directory systems, electronic encyclopedias, file archives, Internet resources, etc.);

- involving the trainee into virtual environment with possibility of imitation of the educational and professional situations initiating manifestation of readiness for the solution of arising problems.

\section{Recommendations}

Practical importance of the research is that its results and conclusions can be used by teachers of history and social science in lesson design in the information-educational environment, definition and analysis of planned educational results, selection of types of the educational activity corresponding to planned educational results, and selection of tutorials for realization of these types of educational activity.

\section{Acknowledgments}

The work is performed according to the Russian Government Program of Competitive Growth of Kazan Federal University

\section{References}

Andreev, A. A. (2004). Some problems of pedagogy in modern information and educational environments. Innovations in education, 6, 98-113.

Baranov, S. P. (1981). Essence of process of training. Moscow.

Bespalko, V. P. (2008). Education and training with the use of computers (pedagogy of the third millennium). Moscow. 
Chelyshkova, M. B., Zvonnikov, V. I., \& Davidov, O. V. (2011). Estimation of competences in education. Moscow.

Chernobay, E. V. (2009). A technique of preparation of the teacher to creation of electronic educational resources. Informatics and education, 11, 110-111.

Chernobay, E. V. (2010). A technique of a lesson designing with the use of electronic educational resources. Standards and monitoring in education, 1, 11-13.

Chernobay, E. V. (2011). Technology of preparation of a lesson in modern information educational environment. Moscow.

Chernov, A. V. (2001). Use of information technologies in history and social science teaching. History teaching at school, 8, 40-46.

Choshanov, M. A. (2011). Engineering of training technologies. Moscow.

Grigoriev, S. G. (2008). Informatization of education. Fundamental bases. Tomsk.

Gundyreva, N. L. (2006). Ways of development of key competences of a modern teacher. Formation of key competences of participants of an educational process: Materials of Regional scientific and practical conference. Omsk.

Ivanenko, N. A., Burdukovskaya, E. A., Yunusova, A. B., Mukhametshina, R. F., Letyaev, V. A., Islamova, L. R., \& Yeremeyeva, T. S. (2015). Corporativity as a Condition for Developing Teaching Staff. Review of European Studies, 7(4), 49-53. http://dx.doi.org/10.5539/res.v7n4p49

Ivanova, E. O., \& Osmolovskaya, I. M. (2011). Theory of training in information society. Moscow.

Karnaukhov, I. N. (1997). Methodological bases of the innovative project of school development. Moscow.

Khayrutdinov, R. R. (2014). Museum Conference of 1926 in Kazan. World Applied Sciences Journal, 31(2), 193-195.

Levina, E. Y., Yunusova, A. B., Fayzullina, A. R., Rassadin, S. V., Lotfullin, M. R., Nuriyeva, E. N., \& Vlasova, V. K. (2015). Federal Public Administration Implementation in Vocational Education. Review of European Studies, 7(4), 98-104. http://dx.doi.org/10.5539/res.v7n4p98

Matros, D. Sh. (2000). Forecasting of results of educational process. School technologies, 1, 65-68.

Mikheyev, T. B., \& Chekunova, E. A. (2008) School teacher: self-education. Moscow.

Novikov, A. M. (2005). Methodology of educational activity. Moscow.

Novikov, A. M. (2008). Post-industrial education. Moscow.

Selevko, G. K. (1998). Modern educational technologies. Moscow.

Shmelyova, L. M. (2015). The Competent and Inter-Disciplinary Approach in Setting up Students' Independent and Science-Oriented Research Work (On the Example of Teaching "The History of the Ancient World"). Journal of Sustainable Development, 8(4), 7-14. http://dx.doi.org/10.5539/jsd.v8n4p7

Smirnova, I. V. (2012). Preparation of the teacher for work in the information educational environment. Modern education - to the society of the XXI century: materials of scientific and practical student's and teaching conference. Noginsk.

Solovyeva, L. F. (2003). Computer technologies for the teacher. St. Petersburg.

Stolyarov, A. M. (2015). Methodology for the Study of Political Historical Geography of Russia in the System of Higher Education. Journal of Sustainable Development, 8(4), 1-6. http://dx.doi.org/10.5539/jsd.v8n4p1

Tuhvatullin, A. H. (2015). The Debate about Methods of Using the Laboratory Plan (Dalton Plan) of During History and Social Studies Classes in the "Istorik-Marxist" Journal in 1927. Journal of Sustainable Development, 8(4), 24-31. http://dx.doi.org/10.5539/jsd.v8n4p24

\section{Copyrights}

Copyright for this article is retained by the author(s), with first publication rights granted to the journal.

This is an open-access article distributed under the terms and conditions of the Creative Commons Attribution license (http://creativecommons.org/licenses/by/3.0/). 